\title{
Übersicht
}

Obere Extremität 2020 $\cdot 15: 228-232$

https://doi.org/10.1007/s11678-020-00578-w

Received: 12 September 2019

Accepted: 14 May 2020

Published online: 3 June 2020

(c) The Author(s) 2020

\author{
Mark Tauber ${ }^{1,2}$ (ID - Peter Habermeyer ${ }^{1}$. Nikolaus Zumbansen ${ }^{1}$. \\ Frank Martetschläger ${ }^{1,3}$ \\ ' Deutsches Schulterzentrum, ATOS Clinic Munich, Munich, Germany \\ ${ }^{2}$ Department of Orthopaedics and Traumatology, Private Paracelsus Medical University, Salzburg, Austria \\ ${ }^{3}$ Department of Orthopaedic Sports Medicine, Klinikum rechts der Isar, Technical University Munich, \\ Munich, Germany
}

\section{Lateral acromioplasty for correction of the critical shoulder angle}

Therefore, the purpose of this arti-

\section{Video online}

The online version of this article contains one video. The article and the video are available online (https://doi.org/10.1007/ s11678-020-00578-w). The video can be found in the article back matter as "Electronic Supplementary Material".

\section{Background}

The bony morphology of the acromion is well known to determine mechanical outlet impingement and represents a risk factor for the development of rotator cuff tear (RCT; $[4,18]$ ). In 1986, Bigliani et al. [4] introduced the wellestablished classification including three types of acromion shape in the outlet view. However, no statistically significant correlation could be shown in regard to RCT. Among others, the critical shoulder angle (CSA) represents a significant radiological parameter correlated with RCT, first described by Moor et al. [17]. It is defined by a line through the superior and inferior glenoid poles and a second line through the inferior glenoid pole and the lateral acromion edge (• Fig. 1). Resection of the lateral acromion edge in patients with a pathological CSA and RCT is suggested in order to normalize the CSA and to prevent RC re-tearing. To date, only cadaveric studies exist describing the influence of lateral acromion resection on the CSA. cle is to describe the arthroscopic technique of acromioplasty with resection of the lateral acromion edge ( $\mathrm{LA}=$ lateral acromioplasty) thus normalizing a pathological CSA and to report the preliminary clinical and radiological data. In contrast to former preclinical studies that used cadavers, initial clinical experiences and preliminary results of LA are reported.

\section{Preoperative planning}

The CSA is measured on a true anteroposterior (AP) view with a commonly available digital measuring software (- Fig. 1a). The gleno-acromial line (defined by the inferior glenoid pole and the lateral acromion edge) is then moved medially until the digital angle measurement tool shows a normal CSA $\left(<33^{\circ}\right)$. The axis of rotation is the inferior glenoid pole. Now, the distance between the lateral acromion edge and the actual position of the upper end of the glenoacromial line is measured in millimeters (- Fig. 1b). This calculated portion is to be resected during the LA (- Fig. 1c). The CSA is susceptible to measuring errors [24]. Therefore, care must be taken to obtain correct "true AP" views in order to minimize miscalculation related to malrotation. Using the true AP view, interrater reliability has been shown to be as high as 0.993 [5].

\section{Indication}

In the authors' clinical practice, the LA is indicated in the following cases of pathological CSA:

1. Failure of nonoperative treatment including subacromial injections, oral nonsteroidal anti-inflammatory therapy, and physical exercises focusing on head-recentering in patients with an intact RC in terms of isolated therapeutic subacromial decompression

2. Concomitant RC repair in terms of prophylactic subacromial decompression

3. Massive, irreparable RCT in terms of palliative subacromial decompression together with tuberculoplasty

\section{Surgical technique}

The procedure is performed with the patient under general anesthesia combined with an interscalene nerve block and in beach chair position. Preoperative endovenous antibiotic prophylaxis is performed with $1.5 \mathrm{~g}$ cefazoline when RC repair is planned. The shoulder is prepared and draped free. Bony landmarks including the scapular spine, acromion, AC joint, distal clavicle, and coracoid are delineated with a skin marker. A posterior standard viewing portal as well as an antero-lateral and an anterior portal are set (• Fig. 2). Diagnostic glenohumeral arthroscopy is carried out through the standard posterior portal 

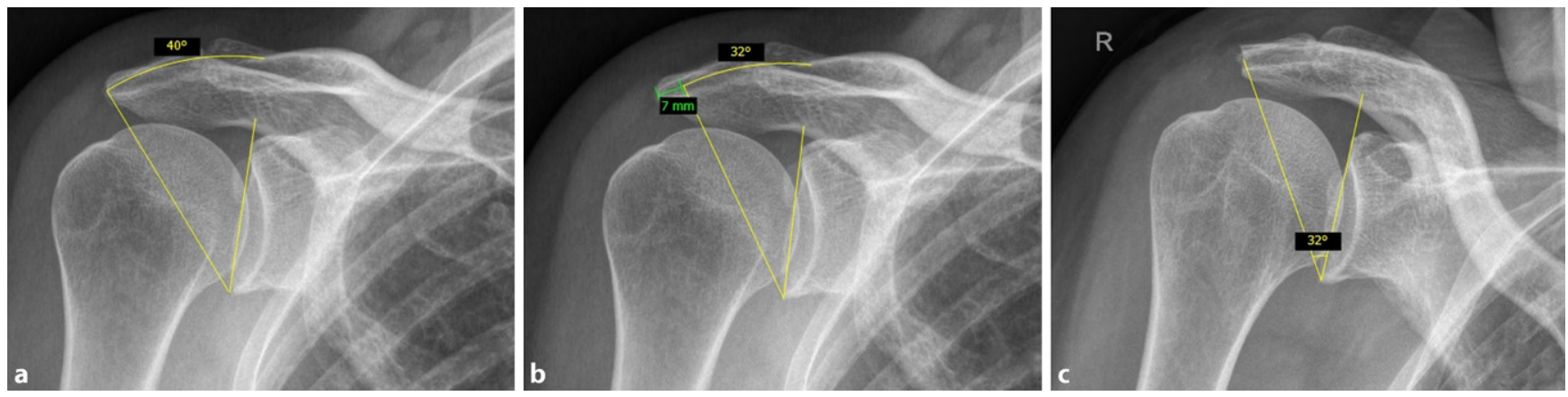

Fig. $1 \Delta$ a Preoperative radiograph showing a pathological critical shoulder angle (CSA) of $40^{\circ}$. b Calculation of the degree of resection, $7 \mathrm{~mm}$ in this case.c Postoperative radiograph showing a normalized CSA of $32^{\circ}$

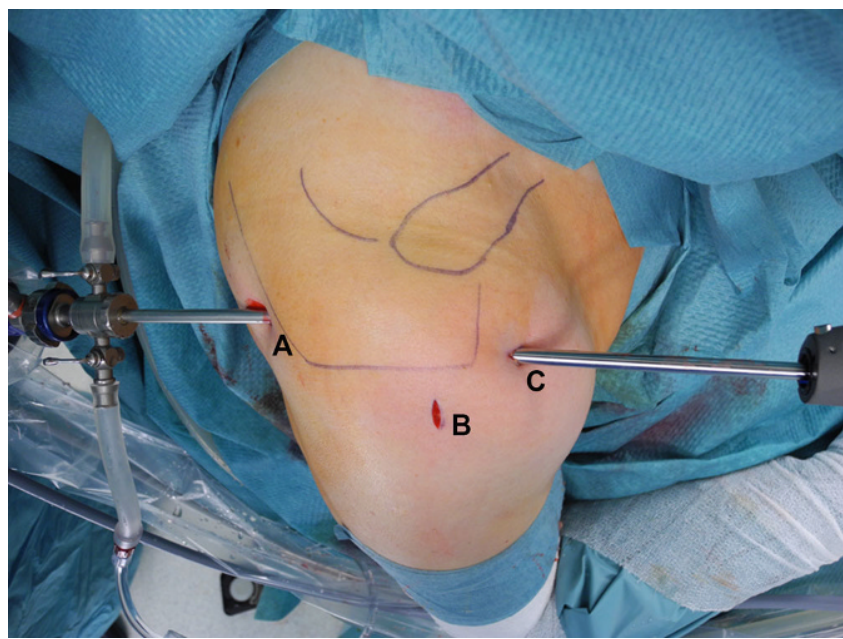

Fig. $2<$ Intraoperative setup and portal placement. $A$ standard posterior portal, $B$ antero-lateral portal, Canterior portal in line with the lateral acromion edge

in order to assess accompanying intraarticular pathologies. After switching in the subacromial space, an antero-lateral portal is established and bursectomy is performed, especially at the anterolateral aspect of the humeral head. The bony circumferences of the anterior and lateral acromion are freed from the periosteum and deltoid muscle origins using an electrocoagulation device. This prevents soft tissue damage and allows for precise bone resection.

Acromioplasty is started via the lateral working portal and should be completed via the posterior working portal to create a flat acromion type I according to Bigliani [4]. The attachment of the coracoacromial ligament should be hereby detached to completely reach the bone spur that is mostly located inside the ligament insertion. A pathological downslope of the acromion (lateral acromion angle [LAA]; [3]) can also be corrected from this portal, if present. The anterior trans-deltoid portal is in line with the lateral acromion edge, which should be proofed with a probe or spinal needle. A 4-mm burr is introduced and resection of the lateral aspect of the acromion is carried out. Attention should be paid to remain in a vertical line and not to harm the deltoid fascia. The degree of bone resection must correlate with the preoperative measurements. The tip of the burr can be used as a caliper for the first cut at the antero-lateral acromial edge (- Fig. 3b). From there, parallel resection in a sagittal direction from anterior to posterior is performed along the lateral acromion preserving the deltoid fascia (• Fig. 3c). The resection is completed through the posterior portal after switching the scope into the anterior portal (• Fig. 3d). Thus, the posterior portal should not be set too far medial from the acromion angle.

Rotator cuff repair, if indicated, is performed as usual. The postoperative treatment does not differ from conventional protocols.

\section{Preliminary results}

Institutional Review Board approval was obtained for this study. Our first series of LA included 20 patients (12 men, 8 women) with an average age of $62 \pm 4.2$ years. All patients underwent arthroscopic RC repair of an isolated supraspinatus tendon tear (mid-size) and an additional LA. The mean preoperative CSA measured $39.7 \pm 1.0^{\circ}$, which was reduced to an average value of $32.1 \pm 1.2^{\circ}$. Short-term follow-up after an average of $16 \pm 2.4$ months showed no re-tear at ultrasound evaluation and an average Constant score of $88.4 \pm 5.5$ points. No local complications were observed at the lateral acromion edge with no evident impairment of the acromial mid-third portion of the deltoid origin.

\section{Discussion}

The importance of the present study lies in the introduction of a new all-arthroscopic technique for normalization of a CSA, which we call "lateral acromioplasty" (LA).

In 1972, Neer [18] published his work on anterior acromioplasty for chronic subacromial impingement syndrome. In 1986, Bigliani et al. [4] classified the shape of the anterior acromion in supraspinatus outlet view into three types. For many years, shoulder surgeons have "corrected" the acromion shape in patients with subacromial impingement or as additional procedure in patients undergoing $\mathrm{RC}$ repair in order to remove the cause of subacromial mechanical conflict or to avoid postoperative stress to the repaired RC. In the past 
few decades, arthroscopic acromioplasty ranged among the most widely performed procedures in shoulder surgery [9].

However, several recent studies have questioned the true benefit of a normalization of the anterior acromial slope. The effectiveness of surgical management of stage II impingement has been investigated in high-quality controlled randomized trials and no significant difference was found compared with the nonsurgical treatment with supervised exercises $[6,8,12]$. Furthermore, it has been shown that outcomes after RCT repair were similar with and without acromioplasty [15, 16]. Probably due to this research, the number of conventional acromioplasties performed has been declining [20].

Recently, new parameters were introduced describing a specific scapula morphology, which might represent pathogenetic factors for RC disease. These parameters, the acromion index (AI) and the CSA, are a matter of current debate among shoulder surgeons.

In 2006 Nyffeler et al. [19] proposed the $\mathrm{AI}$ as the lateral extension of the acromion in relation to the humeral head. Since then, some authors have found significant correlations between high AIvalues and RCT [13, 19, 25]. Other studies could not support this possible association $[2,10]$.

More recently, Moor et al. [17] introduced the CSA, defined as the angle between the plane of the glenoid and the line to the most lateral aspect of the acromion on a true AP view. Large angles have been found to correlate with degenerative RCT, while small angles correlate with osteoarthritis [17, 23] and, as recently published, with SLAP (superior labrum anterior-posterior) lesions [21]. A biomechanical study by Gerber et al. [7] supported the hypothesis that high CSAs can induce supraspinatus overload especially at low degrees of active abduction.

If deemed a pathogenetic factor in the development of degenerative RCTs, a normalization of the CSA might help to avoid future tears or re-tears in patients with pathologically large angles.

So far, no clinical study has been published in the literature describing the

Obere Extremität 2020 15:228-232 https://doi.org/10.1007/s11678-020-00578-w

(c) The Author(s) 2020

M. Tauber · P. Habermeyer · N. Zumbansen · F. Martetschläger

Lateral acromioplasty for correction of the critical shoulder angle

Abstract

The critical shoulder angle (CSA) was introduced as a radiological parameter associated with a higher incidence of rotator cuff tears. As a logical consequence, correcting the CSA together with rotator cuff repair should prevent re-tear and provide reliable and good clinical results. We present an all-arthroscopic technique resecting the lateral edge of the acromion (lateral acromioplasty) in order to reduce and correct the CSA after preoperative planning. Preliminary results from 20 patients with an average age of 62 years after rotator cuff repair are reported showing good clinical outcome with a Constant score of 88 points and no re-tear after an average follow-up of 16 months. The CSA was reduced from $39.7^{\circ}$ to $32.1^{\circ}$. Previous concerns regarding weakening of the deltoid origin were not confirmed and there were no complications linked to lateral acromioplasty.

Keywords

Shoulder - Acromion - Rotator cuff tear . Arthroplasty $\cdot$ Radiography

\section{Laterale Akromioplastik zur Korrektur des kritischen Schulterwinkels}

\section{Zusammenfassung}

Der kritische Schulterwinkel (CSA) wurde als radiologischer Parameter eingeführt und ist mit einer erhöhten Inzidenz an Rotatorenmanschettenrupturen vergesellschaftet. Als logische Konsequenz soll eine Korrektur des CSA die Rerupturrate nach Manschettenrekonstruktion senken und verlässlich gute klinische Ergebnisse liefern. Es wird eine arthroskopische Technik zur Resektion der lateralen Akromionkante (laterale Akromioplastik) mit Korrektur des CSA nach entsprechender präoperativer Planung präsentiert. Vorläufige Ergebnisse bei 20 Patienten mit einem Durchschnittsalter von 62 Jahren nach
Rotatorenmanschettenrekonstruktion zeigen ein gutes Outcome mit einem Constant Score von 88 Punkten ohne Reruptur nach einem Nachuntersuchungszeitraum von 16 Monaten. Der CSA konnte von $39,7^{\circ}$ auf $32,1^{\circ}$ verkleinert werden. Vorausgegangene Bedenken über eine mögliche Schwächung des Deltamuskelursprungs konnten entkräftet werden ohne Komplikationen hinsichtlich der lateralen Akromioplastik.

Schlüsselwörter

Schulter - Akromion - Rotatorenmanschettenruptur · Arthroplastik · Röntgenuntersuchung technique and the preliminary outcomes for normalization of the CSA via an LA. The technique is capable of normalizing the CSA based on preoperative planning. It was shown to be easy, reproducible, and led to a reliable correction of the CSA in the first case series.

The study is limited by the lack of longterm follow-up data. The sample size is quite small, and larger, prospective controlled trials are necessary in order to evaluate the role of LA compared with conventional acromioplasty according to Neer. There was discussion on whether the technique itself might be limited by a potential weakening of the deltoid muscle due to violation of the insertion site or alteration of the pretension. However, the deltoid muscle arises from the superior surface and the anterior surface of the acromion, with prominent tendinous origins from the superior surface [14]. These insertion sites are preserved during the LA procedure. A recent laboratory study by Katthagen et al. [11] reported that the deltoid origin was not damaged when performing an LA. In a second study, the same group showed that LA did not weaken the structural or mechanical integrity of the lateral deltoid origin [11]. In the present study, no clinically evident impairment of the deltoid function was detected. In all patients, a normal CSA was achieved with LA and all patients regained good shoulder function. 

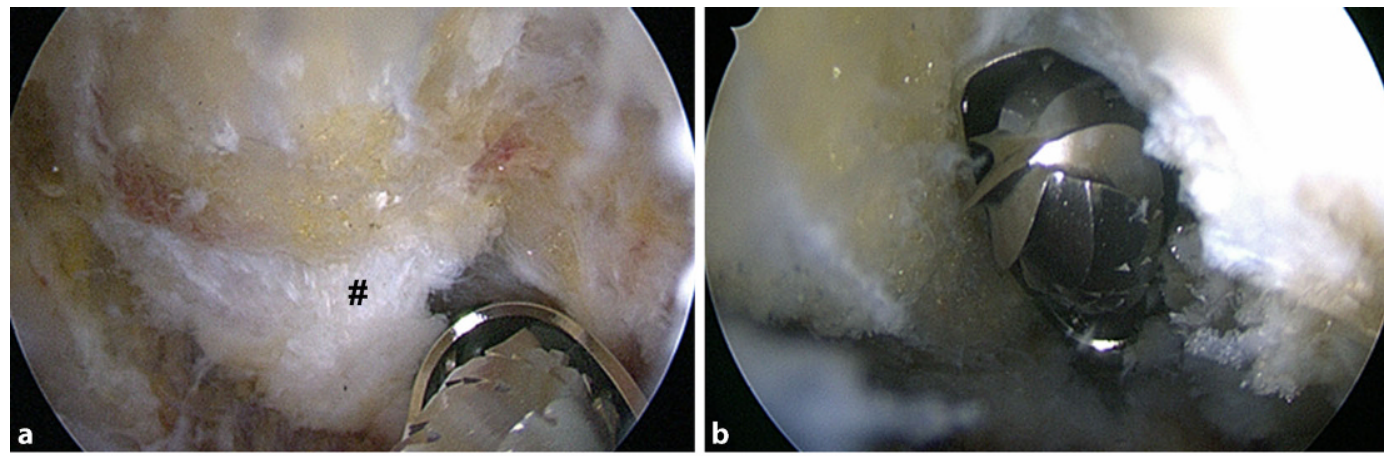

Fig. $3 \triangleleft$ Arthroscopic technique. a The burr is inserted through the anterior portal. Resection is carried out starting from the antero-lateral acromion
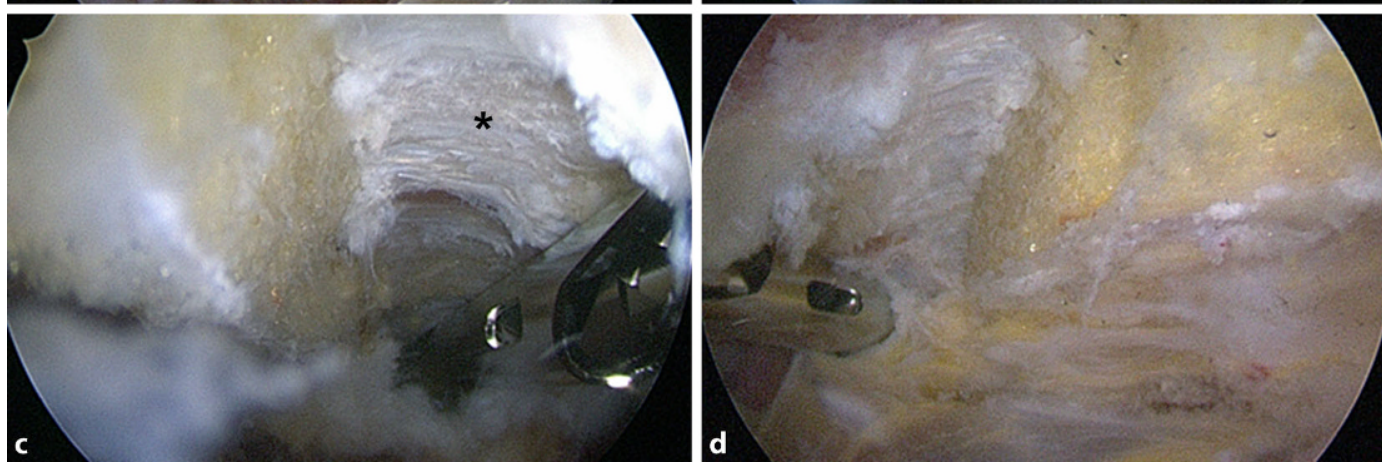
edge. The coracoacromial ligament (CAL) can also be seen (diamond). $\mathbf{b}$ The burr is used as a caliper estimating the amount of resection. c Final resection view from the posterior portal. The intact deltoid fascia can be seen (asterisk). View through anterior portal after finalization of the resection with the burr through the posterior portal

To date, only one study exists in cadaveric shoulder specimens proving the feasibility of a technique for LA [1]. However, no other clinical pilot study exists reporting on the feasibility and preliminary outcomes using an arthroscopic technique for normalization of the CSA in a real operating room setting, where surgical complications, e.g., bleeding, may occur.

Future research will reveal whether this new technique will lead to better clinical results or will end up being declined according to Scott's parabola [22].

\section{Practical conclusion}

- The critical shoulder angle (CSA) is a radiological parameter associated with a higher incidence of rotator cuff tears.

- We present an all-arthroscopic technique-called lateral acromioplasty (LA) - in which the lateral edge of the acromion is resected to reduce and correct the CSA after preoperative planning.

- Preliminary results from our first case series of 20 patients showed that the technique is easy, reproducible, and led to a reliable correction of the CSA.
- No clinically evident impairment of the deltoid function was detected using the LA technique, with all patients regaining good shoulder function.

\section{Corresponding address}

Associate Professor
Mark Tauber, MD
Deutsches Schulterzentrum,
ATOS Clinic Munich
Effnerstraße 38, 81925 Mu-
nich, Germany
tauber@atos.de

Funding. Open access funding provided by Paracelsus Medical University.

\section{Compliance with ethical guidelines}

Conflict of interest. M. Tauber, P. Habermeyer, N. Zumbansen, and F. Martetschläger declare that they have no competing interests.

The study was approved by review board of the clinic. Informed consent was obtained from all individual participants included in the study.

Open Access This article is licensed under a Creative Commons Attribution 4.0 International License, which permits use, sharing, adaptation, distribution and reproduction in any medium or format, as long as you give appropriate credit to the original author(s) and the source, provide a link to the Creative Commons licence, and indicate if changes were made. The images or other third party material in this article are included in the article's Creative Commons licence, unless indicated otherwise in a credit line to the material. If material is not included in the article's Creative Commons licence and your intended use is not permitted by statutory regulation or exceeds the permitted use you will need to obtain permission directly from the copyright holder. To view a copy of this licence, visit http://creativecommons.org/licenses/by/4.0/.

\section{References}

1. Altintas B, Kaab M, Greiner S (2016) Arthroscopic lateral acromion resection (ALAR) optimizes rotator cuff tear relevant scapula parameters. Arch Orthop Trauma Surg 136:799-804

2. Ames JB, Horan MP, Van Der Meijden OA et al (2012) Association between acromial index and outcomes following arthroscopic repair of fullthickness rotator cuff tears. J Bone Joint Surg Am 94:1862-1869

3. Banas MP, Miller RJ, Totterman S (1995) Relationship between the lateral acromion angle and rotator cuff disease. J Shoulder Elbow Surg 4:454-461

4. Bigliani LU, Morrison D, April E (1986) The morphology of the acromion and its relationship to rotator cuff tears. Orthop Trans 10:216

5. Bouaicha S, Ehrmann C, Slankamenac K et al (2014) Comparison of the critical shoulder angle in radiographs and computed tomography. Skeletal Radiol 43:1053-1056

6. Farfaras S, Sernert N, Hallström E et al (2014) Comparison of open acromioplasty, arthroscopic acromioplasty and physiotherapy in patients with subacromial impingement syndrome: a prospective randomised study. Knee Surg Sports 
Traumatol Arthrosc. https://doi.org/10.1007/ s00167-014-3416-4

7. Gerber C, Snedeker JG, Baumgartner D et al (2014) Supraspinatus tendon load during abduction is dependent on the size of the critical shoulder angle: a biomechanical analysis. J Orthop Res 32:952-957

8. Haahr JP, Ostergaard S, Dalsgaard J et al (2005) Exercises versus arthroscopic decompression in patients with subacromial impingement: a randomised, controlled study in 90 cases with a one year follow up. Ann Rheum Dis 64:760-764

9. Habermeyer P, Hansen N, Jung D (1997) Arthroscopic surgical measures in the shoulder joint. Chirurg 68:1085-1092

10. Hamid N, Omid R, Yamaguchi K et al (2012) Relationship of radiographic acromial characteristics and rotator cuff disease: a prospective investigation of clinical, radiographic, and sonographic findings. JShoulder Elbow Surg 21:1289-1298

11. Katthagen JC, Marchetti DC, Tahal DS et al (2016) The effects of arthroscopic lateral acromioplasty on the critical shoulder angle and the anterolateral deltoid origin: an anatomic cadaveric study. Arthroscopy 32(4):569-575. https://doi.org/10 1016/j.arthro.2015.12.019

12. Ketola S, Lehtinen J, Arnala I et al (2009) Does arthroscopic acromioplasty provide any additional value in the treatment of shoulder impingement syndrome?: A two-year randomised controlled trial. J Bone Joint Surg Br 91:1326-1334

13. Kim JR, Ryu KJ, Hong IT et al (2012) Can a high acromion index predict rotator cuff tears? Int Orthop 36:1019-1024

14. Kumar VP, Satku K, Liu J et al (1997) The anatomy of the anterior origin of the deltoid. JBone Joint Surg Br 79:680-683

15. MacDonald P, McRae S, Leiter J et al (2011) Arthroscopic rotator cuff repair with and without acromioplasty in the treatment of full-thickness rotator cuff tears: a multicenter, randomized controlled trial. JBone Joint Surg Am 93:1953-1960

16. Milano G, Grasso A, Salvatore M et al (2007) Arthroscopic rotator cuff repair with and without subacromial decompression: a prospective randomized study. Arthroscopy 23:81-88

17. Moor BK, Bouaicha S, Rothenfluh DA et al (2013) Is there an association between the individual anatomy of the scapula and the development of rotator cuff tears or osteoarthritis of the glenohumeral joint?: A radiological study of the critical shoulder angle. Bone Joint J 95-B:935-941

18. Neer CS 2nd (1972) Anterior acromioplasty for the chronic impingement syndrome in the shoulder: a preliminary report. J Bone Joint Surg Am 54:41-50

19. Nyffeler RW, Werner CM, Sukthankar A et al (2006) Association of a large lateral extension of the acromion with rotator cuff tears. J Bone Joint Surg Am 88:800-805

20. Paloneva J, Lepola V, Karppinen J et al (2015) Declining incidence of acromioplasty in Finland. Acta Orthop 86:220-224

21. Patzer T, Wimmer N, Verde PE et al (2019) The association between a low critical shoulder angle and SLAP lesions. Knee Surg Sports Traumatol Arthrosc 27(12):3944-3951

22. Scott JW (2001) Scott's parabola: the rise and fall of a surgical technique. Br Med J 323:1477

23. Spiegl UJ, Horan MP, Smith SW et al (2015) The critical shoulder angle is associated with rotator cuff tears and shoulder osteoarthritis and is better assessed with radiographs over MRI. Knee Surg
Sports Traumatol Arthrosc. https://doi.org/10. 1007/s00167-015-3587-7

24. Suter T, Gerber Popp A, Zhang Y et al (2015) The influence of radiographic viewing perspective and demographics on the critical shoulder angle. JShoulderElbow Surg 24:e149-e158

25. Zumstein MA, Jost B, Hempel J et al (2008) The clinical and structural long-term results of open repair of massive tears of the rotator cuff. J Bone Joint Surg Am 90:2423-2431 